\title{
Discussion of Construction of Hainan International Tourism Island and Psychological Health of Tourism Area Residents
}

\author{
Duoyu Wu1 ${ }^{10}$, Chunru Wang2* ${ }^{\circ}$, Chenyun $\mathrm{Xu}^{1}{ }^{\circledR}$, Guo Min ${ }^{1}$ \\ ${ }^{1}$ Hainan General Hospital, Haikou, China \\ ${ }^{2}$ People's Hospital of Qionghai City, Qionghai, China \\ Email: 56298a@163.com, ^g2002m@163.com, a56298@163.com,g2002m@163.com
}

How to cite this paper: Wu, D.Y., Wang, C.R., Xu, C.Y. and Min, G. (2020) Discussion of Construction of Hainan International Tourism Island and Psychological Health of Tourism Area Residents. Open Journal of Nursing, 10, 439-448. https://doi.org/10.4236/ojn.2020.104030

Received: March 21, 2020

Accepted: April 24, 2020

Published: April 27, 2020

Copyright (c) 2020 by author(s) and Scientific Research Publishing Inc. This work is licensed under the Creative Commons Attribution International License (CC BY 4.0).

http://creativecommons.org/licenses/by/4.0/

\begin{abstract}
In the ongoing construction of an international tourism island in Hainan, China, the research on the mental health of the residents in the tourism destination is one of the main contents of the research on tourism development. Tourism area is the cell of Hainan International Tourism Island. The mental health service of the residents in the tourism area is an important part of the health work construction of the international tourism island and the basic way to realize the health care for everyone. Nowadays, people's demand for mental health services is far greater than the current supply. In view of the current situation of the limited mental health services provided, we put forward higher requirements and directions for the future development of mental health services in tourist areas. It is planned to carry out the first large-scale publicity and education on mental health of residents in Hainan tourism area in China, and evaluate the effect; carry out a large-scale investigation on mental health of residents in the tourism area, and carry out professional intervention and treatment for patients with mental diseases. Finally, the mental health service network and service institutions covering the tourism areas of Hainan Province were established to provide scientific support for the harmonious and healthy development of the international tourism island in Hainan Province.
\end{abstract}

\section{Keywords}

Hainan International Tourism Island, Psychological Health, Tourism Area

\section{Introduction}

Tourism makes people from different geographical regions, different cultural 
background and economic conditions to contact conditionally, is an economic, cultural interaction behavior between tourists and tourism area residents, and tourists' behavior and their relationship with the local residents can profoundly influence the latter's mental health and their attitude treating visitors [1]. Tourism also changes the local cultural values and psychological behavior to a certain extent, so as to make the ideological and psychological behavior pattern changed [2]. At the same time, the negative effects of the tourism are undertaken mainly by the local community, if ignoring the social and psychological capacity limit and long-term benefits for them, confrontation and conflict might occur and impede the normal operation of the tourism industry, if too serious, it may lead to the harmonious and sustainable development of the tourism industry not achieved [3].

the purpose of this study is to carry out large-scale popular science propagan$\mathrm{da}$ and epidemiological investigation on the mental health of the residents in Hainan tourist destination, so as to find out the mental health of the residents in Hainan tourist destination; to carry out mental health propaganda and education on the residents in Hainan tourist destination, to give psychological intervention to the patients with mental diseases screened out in the transfer, and to cooperate with drug treatment when necessary; to establish The mental health service network of residents in Hainan tourist destination is centered on Sanya, Wuzhishan and the coastal tourist attraction intensive area in the East.

\section{Present Situation and Problems of Mental Health Services in Hainan International Tourism Island Residents}

Psychological study of tourism area residents is one of the main content of tourism development research [4]. Residents of the tourism destination are directly under the tourism impacts, and their attitude of tourism impact would influence planning and development of tourism project. Hainan is constructing the international tourism island, while the negative effect of tourism is mainly undertaken by local residents, neglecting problems of their psychological and social capacity; there will be social confrontation and conflict to hinder the development of the tourism industry and the construction of Hainan international tourism island [5]. The construction of the psychological support system to residents of Hainan tourist area is the prevention, intervention and fast implementation system of social problems of universal psychological dissatisfaction on mental health. Mental health precaution and emergency support system of tourism residents is at the psychological health level firstly [6]. This level is mainly based on the individual's mental health as the object, often solving the psychological problems of some specific living environment, employment, relationship between tourists and residents, as well as some criminal cases and the individual social problems caused by it. The object concerned by social psychology is public panic often caused by individual and social, including social transformation, social injustice, the common psychological feelings and reactions originated by the 
government decision, and thus the common behavioral responses as the resulting [7]. The social psychology problems often lead to turbulence, dissatisfaction and conflict of local or global tourists and residents, and then affect the stability and development of society and the international tourism island.

The residents in the tourism area are the direct bearers of the tourism impact, and their cognitive attitude to the tourism impact will affect the planning and development of tourism projects. However, the negative impact of tourism is mainly borne by local residents. If they ignore their psychosocial bearing capacity and other issues, there will be social confrontation and conflict, which will hinder the development of tourism industry and affect the construction of Hainan International Tourism Island. Therefore, based on Hainan tourist attractions, we carry out mental health education, mental health survey, intervention and treatment services for residents in the tourist area, monitor the mental health level of residents in Hainan tourist area, control and evaluate the needs of mental health services, and finally establish a variety of forms of measurable, testable, operable and feasible A demonstrative mental health service network system for tourist areas.

The State Council clearly pointed out the need to build Hainan into an open island, green island, civilized island, harmonious island with beautiful ecological environment, unique cultural charm, civilized and peaceful society in the file "Several opinions of the State Council on promoting the construction of Hainan international tourism island development" of 2009 (Guo Fa [2009] No. 44). As the only tropical island province of China, Hainan province was established for more than 20 years, with its tourism industry achieved great development, and the tourists multiplied. In 2012, the number of overnight visitors reached $33,203,700$, growing $10.6 \%$ compared to the same period, the number of inbound tourists reached 815,600 , with an increase of $0.1 \%$, carrying out travel gross earnings $37,912,000,000$ Yuan, growing $17 \%$ compared to the same period. In 5 years, the number of overnight visitors increased from 20,600,000 in 2012 to $33,203,700$ in 2008 , total overnight visitors of 5 years amounted to $132,193,800$, with an average annual growth rate of $12.5 \%$; tourism revenue increased from $19,200,000,000$ Yuan in 2008 to 37,912,000,000 Yuan in 2012, accumulative total tourism revenue of 5 years reached 136,484,000,000 Yuan, with an average annual growth rate of $17.2 \%$. In 2010 Spring Festival, the brand effect of International Tourism Island displayed, the tourist structure transformed to further optimization, with the rural tourism, ecological tourism and self driving tourism have become the fashion. The tanker yacht industry tourism develops rapidly. In these more than 20 years, Sanya city became an international tourist city from a small town, attracting worldwide attention [8]. But we also see that in the 264,400 employment population of the most developed tourist city of Sanya, only 7000 local people engaged in high profit tourism. Education in Hainan, decided that most residents of tourism cannot participate in the wealth production chain, has not fully shared the reform and opening up to the Hainan tourism achievements [9]. As everyone knows, Sanya's most famous scenic spot is 
Tianya-Haijiao, however, the mere mention of it, villagers of Tianya town in Sanya and even government officials did not want to hide their grievances: why the ancestors left the natural scenery, they cannot profit, but let developers to circle it and make money. There are hundreds of millions of tourism revenue each year in Tianya-Haijiao, why they can only rely on selling fruit and crafts to earn some money [10]? This also led to many disharmonies of the Hainan tourist attractions, such as consumer fraud, buy and sell unwillingly, stealing and robbery happened occasionally. These problems cannot be simply attributed to the quality of local residents, because a large number of tourists disrupted the local residents living rhythm, tourist psychological capacity of residents of tourism destination has been overloaded, so as to take drastic actions to treat visitors [11]. How to become the islanders' happy island? Deep problems behind this, are still economic planning dominated by the government, how to orient really to the livelihood of the people for both tourism and other industries [12]. So it is very important to understand the psychological health status of local residents, educate them for necessary mental health. Psychological investigation and psychological guidance to residents of Hainan province tourism destination are the direct embodiment of the humanistic concern of government for the residents of tourism. It contributes to government decision-making and the harmonious development of the residents of tourism, and it has important practical significance for the construction of a harmonious society and a stable social situation (see Figure 1).

\section{Developing History of Psychological Health Services of Tourism Residents at Home and Abroad}

The foreign research on effects on tourism destination residents began in 70's of the twentieth Century. Many tourist scholars do qualitative and quantitative research for tourism destination of social carrying capacity [13]. Allen \& Butler and other scholars have used a conceptual model to explain the residents' awareness of the impact of tourism, Bystrzanouski presented the play theory (Play), compensation theory (Compensation) and conflict theory (Conflict), Pearce and Priester are respectively proposed distribution theory (Attribution) and dependency theory (Dependency) to reveal various perceptual phenomena of the tourism impact. Young et al. proposed, in order to eliminate the negative influence of tourism destination caused by the tourism activities, "the government should try to issue a policy; the number of each destination's tourists can reach optimization, not too much and not too little. At the same time, to convince policymakers, make them aware of when the tourist number exceeds a certain limit, it will cause negative effect". D'Amore pointed in the article of "tourism destination district harmonious planning guide" that the tourism social capacity is defined as "the negative effect of the development of tourism activities to the local society reach the critical point that local residents cannot accept". Murphey points out, "provides a framework for social carrying capacity concept for the tourism planning and tourism zone. In this framework, tourism 


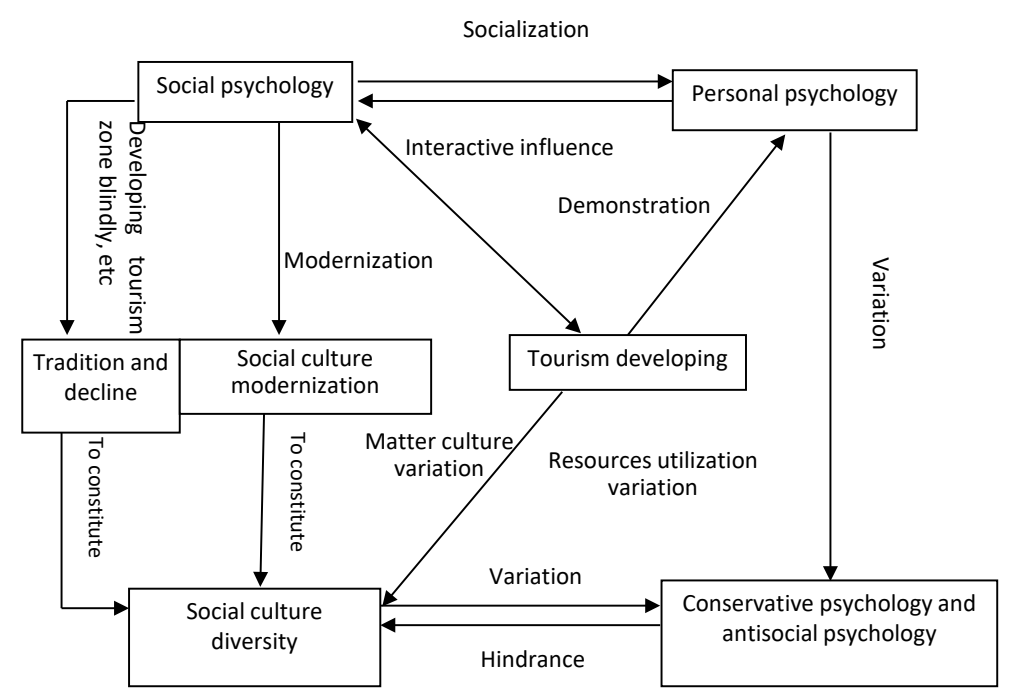

Figure 1. Interactive mechanism among tourism developing, social culture diversity and personal psychological variation.

can be in two planning strategies to choose: one is tourism facilities concentrated layout strategy, another is the tourist facilities scattered layout strategy." Saleem establishes a framework from the social-economic point of view, in order to test the tourism carrying capacity. The psychological impact of tourism in the social culture and tourism area residents, directly related to the normal running of the social life and tourism sustainable development, therefore, to strengthen the research in this area is particularly important.

Tourism district mental health services in western developed countries and regions, started in 50's of the twentieth Century, now the service contents and ways develop in the occupation and diversified, have been relatively mature, and characteristic each other [14]. Such as in the Australian tourism district, mental health services are convenient and thoughtful for others, work carefully, visitors once accepted service, always have a case for the meticulous care and follow-up, until the problem is solved. Service project is widely rich in content, aimed at different groups to carry out a variety of mental health knowledge of different forms of propaganda, counseling and advisory activities. While in Canada, people had received mental health services, more and more back to the tourist areas to provide mental health services, which account for nearly half of the tourist district mental health services personnel. Tourism district mental health service in Swedish belongs to the social welfare projects; but they were mutual association, such as the Psychological Service Consumer and Family Association, has been playing a positive and significant effect. In USA, tourism district mental health service plays a linking role among family, tourist area and normal hospital, formed a wide network of mental health services, is more mature model of mental health service, so all countries in the world have learned and referenced from it. A prominent feature of tourism district mental health service in western developed countries is, social workers, psychologists and psychiatrists join together, even in some way with family doctors working groups to work together. 
Relatively speaking, China's tourism district mental health services started late in the 90's of the twentieth Century, entering a rapid development in the twenty-first Century [15]. Recently the research on the impact of tourism has attracted the attention of domestic scholars. Professor Li Tianyuan pointed out, tourism carrying capacity determines the size limit of sustainable tourism development. Liang Zhi pointed out that tourist destination of social economic carrying capacity includes the tourist benefits, the utility of tourist destination government, tourism enterprises benefits and tourism destination residents utility as the four elements [16]. The net effect of tourism destination of social economic carrying capacity depends on the size of the tourism destination for tourists to get net benefits and tourists in tourism destinations. Scholar Ying Tianyu believe that, for the reality of tourism destination, tourist areas, direct experience influence perception of tourism as the main source of tourist area residents to the local tourism development. The psychological impact of tourism brings the local social culture and tourism district residents, directly related to the reception to the social life and tourism sustainable development [17]. But the tourist district mental health service in China is basically in a single psychological consultation and treatment projects; in addition to the colleges and some related hospital consulting specialized institutions, private consultants although also in blossom everywhere, but can be counted on one's fingers long persist, even insist on down, is the beginning for enterprises to carry out services such as EAP, is not simply a tourist district mental health services, which cannot meet the social base. And even though it has been engaged in psychological counseling and treatment in the community of people, there is quite a part of quality, uneven, some good and some bad phenomenon [18]. In addition, although a few cities such as explored psychological service mode of the tourist areas of Beijing, Shanghai, Hangzhou, Wuhan, Shenzhen and other places, there are also some non support systems professional (such as women's federations, activities, school students internship) in service activities of psychological health tourism; but on the whole, study and the practice of tourism district mental health service in China is not universal and deep, slow development, little effect. In summary, the overall status of psychological tourism zone at present health services in China is still at the starting stage, no tourist district mental health service agency; service range is not wide enough, the way is single, and psychological consulting activities to carry out the actual situation is not optimistic [19]. Therefore, strengthening the work and research in this area is very important.

\section{Model Construction of Psychological Health Service in Tourism Areas of International Tourism Island}

Tourism is the cell of Hainan international tourism island, tourist area residents' mental health service is an important part of health work of international tourism island construction, is the basic approach for realizing health care of everybody. Now the demand for mental health services is far greater than the supply, 
in view of the present status of the limited mental health services, and put forward higher requirements and direction for the development of our tourism district mental health services in the future. However, all aspects of tourism district mental health service related to tourism area, need social units of collaboration and support, to solve the obstacles brought about by the lack of the practice of service personnel, knowledge, technology and place, etc.

1) The participation of government, departments in accordance with the ecological point of view, the individual is a subsystem in the whole ecosystem (including family, school, town, tourism area and city, etc.), therefore, the mental health of the individual related to the individual environment. And the interaction between people and the environment, the individual adjusting at the same time, the environment also needs to be adjusted. Adjustment of the environment requires governments at all levels of health, education and other departments to be involved, the coordination of various departments, agencies, the mental health services as part of a health service system of tourism area to construction; at the same time undertakes the organization related professionals, institutions and colleges system training practitioners; strengthen the supervision, guidance, management and assist practitioners staff to conduct a comprehensive, effective mental health service in time for the tourist area people, promote the overall level of mental health of residents.

2) Based on the tourism area, to carry out activities. Tourism district mental health service must be on the tourist area as the foothold, the creation of mental health service center, the tourist area of psychological counseling institutionalized, standardization. And increase the mental health knowledge popularization efforts, according to the characteristics of tourism area, residents understand the level of psychological knowledge, a mental health promotional materials, set up psychological counseling, mental health books recommended column, regular seminars and other forms, extensive mental health knowledge propaganda, the promotion of new concepts of mental health, improve people's psychological health awareness, prevention for primary psychological problems, so as to achieve early detection and early treatment, further improve the level of mental health of people, to accelerate the development and construction of international tourism island.

3) Emphasis on the unemployed population's level of mental health care, to provide multi-level, multi-form of psychological counseling service contents and methods, so that more people get the care for mental health. At the same time, to strengthen the psychological counseling and education work of the unemployed families, especially those with low cultural quality of the staff mental health counseling, psychological support and more perfect, more system for their self-reliance. When conditions are ripe, together with the tourism employment can be re employment and training combination, tourist service training service and management personnel, help the unemployed themselves to establish the confidence of life, contribute to the construction of harmonious tourist island. 
4) Innovation for service, expansion for project in the tourism area. Different classes, different ages are different for mental health knowledge or ideas, different people, different ages have different employment and psychological needs. Therefore, in the development of mental health education and service of tourism area, it should be diversified to form, be lively to content. Service content in addition to including travel island construction and harmonious, health education, psychological counseling, tourism district harmonious guidance services, should also be timely innovation in the form of services, expand service projects, expanding the scope of mental health services. In the base of the focus groups, mental health services will be extended to other residents, tourism area population, schools, enterprises and institutions, spread knowledge of mental health related to the broader public tourism area, so as to better serve the residents in the tourist areas to provide mental health services.

China is a country with rich tourism resources. Through our large-scale propaganda and epidemiological research on mental health of residents in tourism areas in Hainan Province, we can solve the negative psychological impact of residents in tourism areas in Hainan Province and the resistance of residents in tourism areas to integrate into tourism construction. At the same time, it also has practical reference and guidance significance for other similar tourism area residents' mental health, and will produce significant economic and social benefits.

Service is an important part of the construction of the health work of the international tourist island and the basic way to realize the health care for all. Nowadays, people's demand for mental health services is far greater than the current supply. According to the current situation of the limited mental health services provided, higher requirements and directions are put forward for the future development of mental health services in tourism areas. However, mental health services in tourism areas involve all aspects of tourism areas, and need the cooperation and support of relevant social units, in order to solve the obstacles caused by the lack of service personnel, knowledge, technology and places in practice (see Figure 2).

\section{Conclusion}

In a word, it should be based on the Hainan tourist attractions, carry out mental health education for tourism area residents, intervent services network, monitor mental health level of residents in Hainan tourism area and control and evaluate the system needs for mental health services, and finally set up the service network system model paradigm of tourism area mental health by combining various forms of evaluation, examination, operational, and through application of vulnerability analysis and extension theory, study a model of rational evaluation of tourism area mental health monitoring system, help the government of Hainan to understand the psychological effect of tourism, reduce conflicts between tourists and residents, plan reasonably, in order to obtain residents' support for tourism, to provide a scientific basis for the construction of Hainan international 


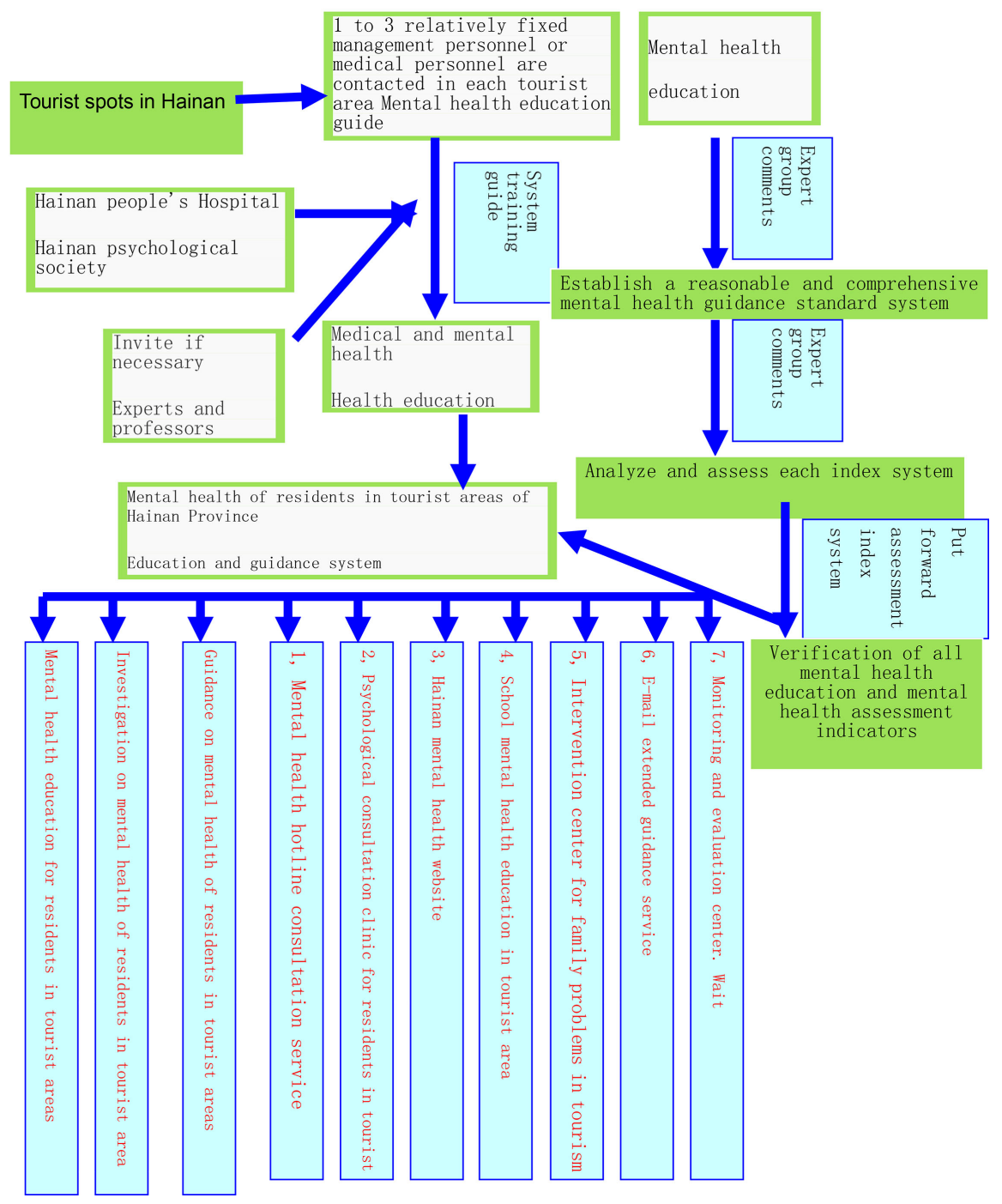

Figure 2. Implementation plan.

tourism island to improve the psychological quality. To strengthen the mental health education for tourism area residents, prevent and reduce the adverse psychological and behavioral problems, related to prosperity and stability of the tourism area residents' physical and mental health, it has the important role and far-reaching historical significance for ensuring economic and social comprehensive, harmonious and sustainable development in Hainan Province.

\section{Foundation Project}

Hainan Health Commission Science and Technology Project (No. 20A200210).

\section{Conflicts of Interest}

The authors declare no conflicts of interest regarding the publication of this paper.

\section{References}

[1] Yang, J.L. (2012) Discussion on the International Tax-Free Policy and Hainan 
Tax-Free Policy. Business Accounting, 13, 36-38.

[2] Jiang, X.L., Cai, J.H., Gao, Y.S. and Wu, D.Y. (2010) Discussion on the Construction of Mental Health Service Network in Hainan Tourist Destination. Tropical Medicine of China, 4, 515-516.

[3] Liang, W.B. and Shi, W. (2012) A Study on the Influence of Cross-Cultural Tourism on the Psychology and Behavior of the Residents in the Tourist Destination: A Case Study of the Local Residents in Dunhuang. China Agronomy Bulletin, 6, 312-316.

[4] Chen, Z.J., Yang, H., Liu, J.Y. and Deng, Q.Z. (2014) An Empirical Study on the Influencing Factors of Residents' Psychological Satisfaction in Shaoshan City, a Red Tourist Destination. Contemporary Education Theory and Practice, 122-125.

[5] Zhang, B. (2014) A Study on the Social and Psychological Carrying Capacity of the Residents in the Tourist Destination: A Case Study of Asakushi Temple in Tokyo, Japan. Journal of Tourism Science, 12, 55-65.

[6] Gong, J. (2016) A Study on Residents' Perception of the Impact of Festival Tourism: Taking Suzhou International Tourism Festival as an Example. Intelligence, 33, 264-265.

[7] Tang, J. and Wei, X.F. (2019) A Study on the Influence of Policy Support and Psychological Capital on the Willingness of Farmers to Start a Business in Tourism: A Case Study of Shibadong Village in Western Hunan. Journal of Huaihua University, 1, 29-35.

[8] Xie, G.Z. and Chen, Y.S. (2019) A Study on the Tourism Practitioners' Perception of Tourism Impact: A Case Study of Hainan, China. Ecological economy, 5, 168-176.

[9] Liao, L. (2015) Thinking on Promoting the Development of Leisure Agriculture in China by Learning from Foreign Experience. World Agriculture, No. 5, 133-135.

[10] Shao, X.H. and Xin, J.R. (2016) Research and Development of Leisure Agricultural Products in Hainan Based on RMC P Analysis. World Agriculture, No. 6, 208-211.

[11] Zheng, W.M., Chen, S.Q. and Yang, S.Y. (2011) Research on the Development of Ecological Leisure and Sightseeing Agricultural Tourism: Taking Quanzhou City, Fujian Province as an Example. Anhui Agricultural Science, No. 36, 22432-22434.

[12] Yan, X.F., Huang, J. and Zhang, W. (2015) Study on the Conditions and Strategies for the Development of Leisure Agriculture Industry in Hainan. Agricultural Mechanization Research, No. 5, 14-19.

[13] Kong, T.T. (2013) Study on the Relationship between Psychoelasticity and Influencing Factors and PTSD. Xinjiang Medical University, Halmurat Upur, 1-68.

[14] Yu, H. (2016) Psychological Nursing Intervention in Post-Traumatic Stress Disorder Anxiety and Nursing Research. Chinese Medical Guide, No. 1, 226-227.

[15] Lei, A. (2013) Cognitive Characteristics of Different Psychological Types. Jiangxi Normal University, Nanchang, 1-48.

[16] Wang, T. (2014) Cultural Adaptation of Li Nationality: Characteristics, Influencing Factors and Theoretical Model.

[17] Shan, X.Z. (2011) Research on the Relationship between MBTI Personality Type and Psychological Capital of College Students. Nanjing Normal University, Nanjing, 1-53.

[18] Ao, X.L. (2004) An Overview of Psychological Type Theory. Journal of Southwest University for Nationalities (Philosophy and Social Sciences Edition), No. 1, 393-397.

[19] Gao, Q.W. and Li, G.L. (2014) Analysis on Investment Environment of Leisure Agriculture Based on SWOT Model. Agricultural Engineering, No. 2, 95-99. 